\title{
A sua empresa, como está?
}

\section{O uso dos dados do IBGE para pesquisa e planejamento estratégico das indústrias dos setores químico e farmacêutico de Goiás}

No ambiente cada vez mais globalizado e competitivo em que as empresas se inserem na atualidade, para aumentar sua competitividade, ou mesmo para se manter no mercado, é preciso reavaliar constantemente as práticas gerenciais adotadas e situar-se em relação ao mercado. Para tanto, ter e saber utilizar as informações disponíveis sobre a economia e sobre seu setor de atividade é fundamental. Segundo o $\operatorname{IBGE}^{1}$ (2010), de 2007 para 2008 sobreviveram 78\% das empresas ativas em 2007. Esta porcentagem foi de $68 \%$ para empresas sem pessoal ocupado e de $89 \%$ para empresas com até nove funcionários. De acordo com o SEBRAE 2 , a taxa de sucesso de uma empresa está relacionada diretamente a análises prospectivas relacionadas à viabilidade econômica do negócio. Um estudo realizado com 1961 empresas de São Paulo entre 1999 e 2003 mostrou que a sobrevivência das empresas investigadas no estado se relacionou principalmente com práticas gerenciais adotadas pelas mesmas. Estas práticas gerenciais, por sua vez,. envolvem principalmente o estabelecimento de objetivos e metas, a busca de informações e a antecipação de acontecimentos, de acordo com os objetivos estabelecidos $\mathrm{O}$ estudo revela ainda que, em geral, as maiores empresas são as que mais adotam esse tipo de prática gerencial e, não por acaso, são as que têm maior taxa de sobrevivência.

Ao estabelecer objetivos e metas, não é incomum a realização de estudos de viabilidade econômica para a implantação de uma empresa ou de uma nova unidade de uma empresa. De fato, várias empresas de consultoria vendem serviços dessa natureza a empresas que queiram se estabelecer, se restabelecer em outras regiões ou mesmo expandir suas atividades. Os serviços disponíveis variam da pura análise demográfica, que envolve aspectos sociais que focam na mão de obra disponível, nas regiões foco da empresa contratante, até os estudos de geomarketing. Um serviço mais completo envolve a avaliação de possibilidades de incentivos fiscais, qualificação da mão de obra, parcerias, etc.

Nesta perspectiva, os dados coletados pelo IBGE podem ser de extrema utilidade pois, além do Censo Demográfico e da contagem populacional realizados a cada dez anos, as pesquisas do IBGE fornecem acompanhamento um contínuo da estrutura do setor produtivo, como receitas, gastos, despesas, salários (como as pesquisas anuais de indústrias, serviços, comércio e indústria da construção); de receitas e despesas da administração pública federal, estadual e municipal; de índices de preços e vendas no comércio varejista e produção industrial, coletados mensalmente; além de pesquisas de orçamento familiares e de estruturas domiciliares, saneamento básico, inovação tecnológica, dentre outros. Em conjunto, fornecem o retrato mais amplo e, ao mesmo tempo, pormenorizado, da nossa realidade, permitindo entender as variações sociais e econômicas ocorridas em nosso país ao longo dos anos.

Para se ter uma ideia disso, basta ter em mente que uma breve pesquisa em buscadores na internet com o termo IBGE (excluindo-se o próprio site do IBGE) retorna mais de 1.500 .000 páginas, o que mostra que estes dados tem sido utilizados e indica que isto pode ter papel decisivo para as empresas ao fornecer diferenciais competitivos. Por isso gostaríamos de salientar dois pontos: 1) como os dados obtidos pelo IBGE podem ser utilizados para a realização de análises de viabilidade econômica? 2) após o estabelecimento da empresa, como o empresário pode acompanhar a evolução de sua empresa em relação a outras do mesmo ramo, seja na sua região, seja em outros locais. Que dados podem ser utilizados pelas empresas, onde eles estão? 
Para direcionar esta questão e mostrar como esses dados podem contribuir para avaliação e planejamento estratégico das empresas, apresentaremos uma breve análise da evolução do setor industrial de Goiás em relação ao Centro-Oeste e ao Brasil, enfatizando as variações de receita e despesas do setor químico e farmacoquímico de Goiás entre 2007 e 2008, conforme a Pesquisa Industrial Anual ${ }^{4,5}$. Serão ainda, apresentados alguns dados referentes à Pesquisa Industrial MensalProdução Física Regional ${ }^{6}$ para o período de março de 2009 a março de 2011.

\section{A Indústria Goiana no período recente}

A indústria goiana concentrava em 2008, 1165 unidades locais industriais, englobando indústrias extrativas e indústrias de transformação. Este número correspondia a cerca de $3 \%$ do total de unidades do Brasil e 51,8\% do total do Centro-Oeste. Estes dados são apresentados na Tabela 1, que mostra também os valores de Pessoal Ocupado (PO) em 31 de dezembro (2,49\% e 51,3\%, em comparação ao Brasil e ao Centro-Oeste, respectivamente), salários (1,69\% e 50,99\%), custos e despesas gerais (2,64\% e 52,09\%) e despesas industriais (2,73\% e 49,96\%), receita líquida de vendas industriais (2,4\% e 51,35\%), consumo de matérias-primas (2,88\% e 50,09\%) e Valor da Transformação Industrial - VTI (1,89\% e $51,51 \%)$.

Tabela 1. Dados Gerais da Indústria Goiana em Relação ao Brasil e ao Centro-Oeste - 2008

\begin{tabular}{|c|c|c|c|}
\hline Variáveis & Totais & $\begin{array}{c}\text { \%GO__ } \\
\text { BR_2008 }\end{array}$ & $\begin{array}{c}\text { \%GO__ } \\
\text { CO_2008 }\end{array}$ \\
\hline Número de unidades locais (UL) & 1165 & 2,97 & 51,80 \\
\hline Pessoal ocupado em 31.12 (PO) & 29458 & 2,49 & 51,34 \\
\hline $\begin{array}{c}\text { Salários, retiradas e outras } \\
\text { remunerações (SAL) }\end{array}$ & 280503 & 1,69 & 50,99 \\
\hline Custos e despesas (DESP) & 3759123 & 2,64 & 52,09 \\
\hline $\begin{array}{c}\text { Receita líquida de vendas } \\
\text { industrial (REC IND) }\end{array}$ & 3250853 & 2,40 & 51,35 \\
\hline $\begin{array}{c}\text { Custos das operações industriais } \\
\text { (CUSTOS IND) }\end{array}$ & 2215363 & 2,73 & 49,96 \\
\hline $\begin{array}{c}\text { Consumo de matérias- } \\
\text { primas, materiais auxiliares e } \\
\text { componentes (MAT) }\end{array}$ & 2033627 & 2,88 & 50,09 \\
\hline $\begin{array}{c}\text { Valor da transformação } \\
\text { industrial (VTI) }\end{array}$ & 1353411 & 1,89 & 51,51 \\
\hline
\end{tabular}

Fonte: IBGE (2010). Pesquisa Industrial Anual.
Quanto à relação entre os dados de PO e salários, observamos que os $51,34 \%$ do pessoal ocupado em Goiás em relação ao Centro-Oeste são responsáveis por 50,99\% dos salários da região, o que indica uma média salarial na indústria abaixo do Centro-Oeste. Quando comparada com o Brasil, a queda nas médias salariais é ainda maior, visto que $2,49 \%$ do $\mathrm{PO}$ alocado nas indústrias em Goiás representa apenas 1,69\% dos salários pagos na indústria brasileira. Certamente, essas diferenças têm relação com o tipo de indústria em cada região. Contudo, é importante observarmos um dado como este, visto que pode repercutir diretamente sobre a captação e fixação de mão de obra no Estado, notadamente aquela com maior qualificação.

Apesar destes salários e do baixo índice relativo de custos e despesas industriais, conjugado ao baixo consumo de matérias-primas relativamente à porcentagem de ULs, verificamos que o VTI estadual em relação ao nacional apresenta um valor relativamente baixo. Estes dados podem representar diversas relações, como baixo aproveitamento de matérias-primas, pouca racionalização nos gastos/alocação de despesas, baixo nível de produção ou a necessidade de praticar preços mais competitivos como forma de ultrapassar os problemas derivados de questões logísticas. Há ainda que se observar a possível relação disso com custos operacionais como transporte (de insumos, matériasprimas ou dos produtos industrializados).

\section{Os setores químico, farmacoquímico e farmacêutico de Goiás nos últimos anos - análise estrutural}

Além dos dados referentes ao setor industrial como um todo, o IBGE fornece acompanhamento anual e mensal da indústria extrativa e dos diversos setores da indústria de transformação, como fabricação de produtos químicos e fabricação de produtos farmacoquímicos farmacêuticos. Ao longo dos anos, podemos observar como a estrutura destes setores se configura quanto à sua participação em relação às indústrias de transformação em Goiás e também no tocante aos respectivos setores no Brasil.

Com esses dados em mão as variações observadas no estado (crescimento ou retração) podem ser analisadas à luz das variações gerais da indústria de transformação localmente indicadas, enquanto as variações nos respectivos setores podem ser avaliadas quanto às variações em nível nacional. Mensalmente, índices de receitas, salários e produção proveem indicadores dessas variações em comparações a curto prazo, médio prazo ou longo prazo . 
E, certamente, de posse de dados próprios e dados gerais como os aqui apresentados, uma determinada indústria pode se localizar em relação às demais indústrias do ramo e avaliar sua estrutura, suas receitas, seus gastos e, se necessário, rever suas próprias práticas gerenciais. Aqui, vale lembrar da importância da revisão periódica das práticas gerenciais apontada no estudo supracitado.

Para ilustrar como as análises podem ser feitas, vamos inicialmente fazer uma comparação entre as indústrias de Goiás entre 2007 e 2008. Foi apontada acima a participação das indústrias de Goiás em relação ao Centro-Oeste e ao Brasil. Abaixo, a Figura 1 apresenta como variaram em Goiás as porcentagens de Unidades Locais (UL), Pessoal Ocupado (PO), Salários, Receita Industrial, Custos Industriais e VTI. Estas variações são apresentadas para o setor industrial como um todo, para as indústrias de transformação, para o setor de fabricação de produtos químicos e, por último, fabricação de farmacoquímicos e farmacêuticos (IBGE, 2009, IBGE, 2010).

Com relação às ULs, pode-se ver que o número aumentou em torno de $4 \%$ tanto para a indústria em geral quanto para as indústrias de transformação. Por outro lado, no mesmo período houve, no estado, diminuição no total de ULs de indústrias do setor químico e do setor farmacoquímico/farmacêutico. Esta diminuição foi mais acentuada para o setor farmacoquímico/ farmacêutico, que teve uma redução de 13\% nas ULs. Os dados indicam que, enquanto o setor industrial de Goiás se expandiu no período, os setores de fabricação de produtos químicos e de fabricação de produtos farmacoquímicos/farmacêuticos sofreram retração em relação ao número de ULs.

Para os demais dados apresentados, todos os setores apresentaram aumento na comparação entre 2007 e 2008, conforme será visto a seguir. O crescimento de PO e Salários das indústrias químicas e farmacoquímicas/ farmacêuticas foi menor que o crescimento das indústrias em geral e das indústrias de transformação em Goiás. Enquanto para a indústria em geral e as indústrias de transformação o PO e os salários pagos tiveram aumento de $10 \%$ e $26 \%$, respectivamente, os crescimentos do PO foram de $6 \%$ (químico) e $5 \%$ (farmacoquímico/ farmacêutico), e os de salários foram de 19\% e 14\% para os mesmos setores.

De 2007 para 2008 houve um crescimento médio de 19\% na receita industrial das indústrias de transformação de Goiás. Com relação às indústrias químicas e farmacoquímicas/farmacêuticas, podemos observar tendências diferentes. Enquanto o setor químico apresentou 29\% de crescimento na receita industrial, o setor farmacoquímico/farmacêutico teve aumento médio na receita de $14 \%$, ligeiramente abaixo dos dados da indústria geral e metade do crescimento do setor químico. Em contrapartida, neste período o setor químico apresentou aumento de $68 \%$ nos custos industriais, quase três vezes maior que a média das indústrias de Goiás, que foi de 25\%, enquanto o setor farmacoquímico/ farmacêutico teve aumento de $19 \%$ nos custos.

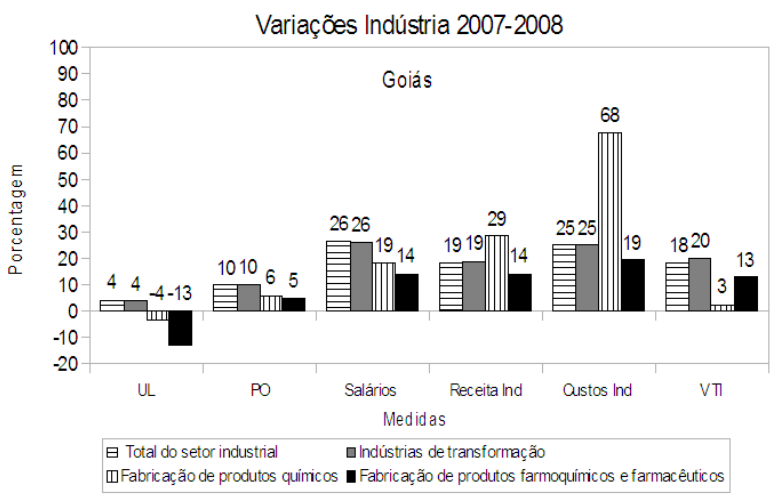

Figura 1. Variações em Unidades Locais (ULs), Pessoal Ocupado (PO), Salários, Receitas Industriais, Custos Industriais e VTI em Goiás para o setor industrial, para as indústrias de transformação e para fabricação de produtos químicos e farmacoquímicos/farmacêuticos de 2007 a 2008. Fonte: IBGE. Pesquisa Industrial Anual (2007) e (2008).

Juntamente a outras medidas, estes dados tiveram implicações para as diferenças no aumento do VTI no período em que as indústrias de transformação de Goiás teve um aumento no VTI de 20\% em 2008, em comparação com 2007. Os aumentos nos VTIs dos setores químicos e farmacoquímicos/farmacêuticos foram de $3 \%$ e $13 \%$, menores que o crescimento percentual médio das indústrias de transformação de Goiás se relacionam diretamente ao baixo aumento nas receitas industriais para o setor farmacoquímico/ farmacêutico, e o aumento muito acima da média nos custos industriais para o setor químico.

Apesar de ter crescido de 2007 para 2008, os dados para o setor farmacoquímico/farmacêutico apresentam ligeira expansão no número de ULs relativamente ao Centro-Oeste, mas uma diminuição no PO, nos Salários, receita e custos industriais no período. Estes dados fizeram com que o setor, responsável por quase $100 \%$ do 
valor de transformação industrial do Centro-Oeste em 2007, passasse a representar menos de 80\% em 2008.

\section{A produção física do setor químico de 2009 a 2011}

Os dados referentes à estrutura geral das indústrias, conforme disponibilizados na publicação da Pesquisa Industrial Anual, tem uma grande amplitude e permitem um entendimento mais geral dos setores investigados. Além desses dados, mensalmente temos indicadores sobre a produção industrial no Brasil e regionalizada para 13 unidades da federação e região nordeste, divulgados pela PIM-PF (Pesquisa Industrial Mensal - Produção Física), que permitem acompanhar a produção de cada setor em relação ao mês anterior, ao mesmo mês do ano anterior, ao longo de 12 meses em relação aos 12 meses imediatamente anteriores e no ano corrente. O indicador que compara o mês de referência com o mesmo mês do ano anterior pode, por exemplo, ser acompanhado ao longo de um período, de forma a se saber como a produção variou em vários meses em relação aos respectivos meses do ano anterior. Para exemplificar, a Figura 2 apresenta a comparação da produção de produtos químicos para os estados do Amazona, Ceará, Pernambuco, Bahia e Goiás ao longo de um período de 25 meses, iniciando em março de 2009 até março de 2011. A medida base é 100, que indica que a produção do mês em análise foi igual à produção no mesmo mês do ano anterior. Valores acima de 100 implicam em uma maior produção, ao passo que valores abaixo dessa medida indicam que a produção do mês em questão foi menor que no mesmo mês do ano anterior.

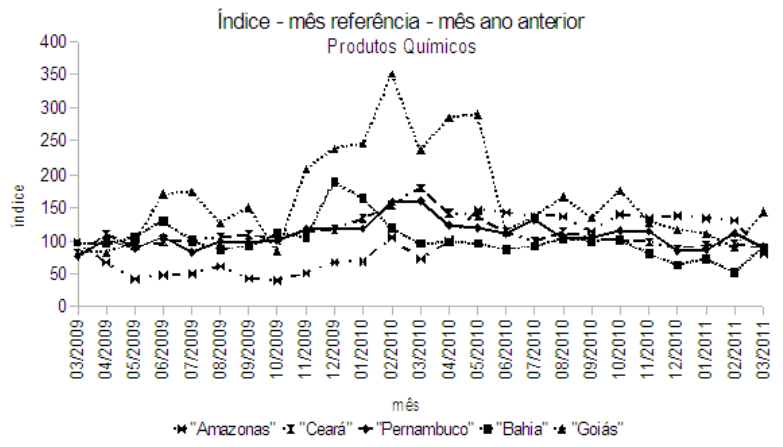

Figura 2. Índice de Produção Física na comparação do mês de referência com o mesmo mês do ano anterior para as indústrias de fabricação de produtos químicos nos estados do Amazonas, Ceará, Pernambuco, Bahia e Goiás para o período de março de 2009 a março de 2011. Fonte: IBGE PIM-PF Regional, publicações mensais - abril de 2009 a abril de 2011
Pode-se observar que a produção no mês de março de 2009 ficou abaixo de 100 para todos os estados citados, o que representa uma produção menor que a observada no mesmo mês de 2008. O estado do Amazonas apresenta produções ainda mais baixas que nos respectivos meses do ano anterior quando analisados os índices obtidos de abril de 2009 a março de 2010. Após este período, o setor apresenta um aumento na produção mensal em relação ao mesmo mês do ano anterior. Para Ceará e Pernambuco, há uma manutenção na produção ao longo dos meses, com produção ligeiramente maior que a do respectivo mês do ano anterior para a maior parte do período. A produção do setor na Bahia concentra-se na maior parte do período abaixo dos meses de referência do ano anterior, exceto pela produção dos meses de outubro de 2009 a fevereiro de 2010.

Quanto a Goiás, a produção mensal apresenta crescimentos significativamente maiores em comparação aos respectivos meses do ano anterior do que os observados para as unidades da federação com dados disponíveis apresentadas acima. Ao longo do tempo, a produção comparada com os respectivos meses dos anos anteriores foi maior, em alguns casos mais que o dobro, como no período que compõe os meses de novembro de 2009 a maio de 2010. Produção inferior ao mês correspondente do ano anterior, de acordo com esta medida, ocorreu apenas apenas nos meses de março, abril, maio e outubro de 2009, e fevereiro de 2011.

\section{Considerações Finais}

Podemos retornar agora à nossa questão inicial: E sua empresa, como está? Ela tem crescido, tem tido retração? Este crescimento ou retração é comparável ao que foi apresentado para as indústrias de Goiás e, mais especificamente, para os setores de fabricação de produtos químicos e de fabricação de produtos farmacoquímicos/farmacêuticos? Em alguns casos, as mudanças ocorridas em uma empresa são decorrentes de fatores externos a ela, como aspectos econômicos ou sociais no país. Como falamos ao início, muitas vezes as empresas avaliam estes aspectos ao implantar suas unidades, mas deixam de acompanhá-los após esta fase. Mas como as mudanças nesses aspectos são dinâmicas, acompanhá-las é fundamental para o estabelecimento de estratégias. 
O presente trabalho fornece dados importantes para serem considerados pelas indústrias e, mais especificamente, pelas empresas dos ramos químicos e farmacoquímicos/farmacêuticos. Eles mostram que o nível de eficiência (medido pelo VTI) das ULs de Goiás é comparável ao do Centro-Oeste, mas está abaixo do nacional. Em relação mais especificamente ao setor químico, a diminuição de ULs de 2007 para 2008 não representou diminuição na produção em relação ao Centro-Oeste. Mais ainda, Goiás tem mantido produção crescente, quando comparada com os respectivos meses dos anos anteriores e principalmente quando comparado a outras Unidades da Federação. Devemos observar ainda que, no estado, o crescimento do VTI nos dois setores analisados de 2007 para 2008 foi menor que o crescimento industrial geral, o que pode indicar um desaquecimento.

A brevidade das análises aqui apresentadas objetiva levar o setor produtivo a atentar para esses pontos. Certamente que há muito mais a considerar, pois a produção é afetada por diversos fatores. Ao se pensar em diferencial competitivo a empresa pode considerar, por exemplo, alternativas, utilização de métodos para racionalização da produção, análises logísticas, qualificação de pessoal. Cada empresa tem acesso a seus próprios relatórios e pode utilizar os dados disponíveis no IBGE e em outros órgãos, conforme suas necessidades. A grande vantagem de ter dados comparativos é exatamente poder compreender se estamos crescendo tanto quando poderíamos, ou se estamos nos retraindo mais do que deveríamos.

Às vezes empresários pensam que o retorno de pesquisas como estas é muito baixo ou que favorece apenas o Governo. Não há como discordar que esses dados devem favorecer o Governo, mas como forma de subsidiar ações em prol dos diversos setores da sociedade. Mas, como mostramos acima, não é apenas ele que pode se beneficiar dessas informações. Pelo contrário, há diversos dados disponíveis, não apenas nas pesquisas aqui apresentadas, mas nas diferentes pesquisas sociais e econômicas, como indicamos ao início deste trabalho, o que permite ao IBGE fornecer o retrato mais completo do Brasil. Esses dados são construídos com a participação efetiva da própria sociedade, a partir de sua população e das empresas dos diferentes setores. O fornecimento de informações precisas e constantes ao órgão são assim, ponto fundamental para que os informantes possam obter os melhores benefícios.

\section{Referências}

1. Instituto Brasileiro de Geografia e Estatística. Demografia das Empresas 2008. Rio de Janeiro: IBGE.

2. SEBRAE. Boletim estatístico de micro e pequenas empresas. Observatório SEBRAE $1^{\circ}$ semestre 2005. 2005, p. 1 - 80.

3. Mizumoto, F. M.; Artes, R.; Lazzarini, S. G.; Hashimoto, M.; Bedê, M. A.. A sobrevivência de empresas nascentes no Estado de São Paulo: um estudo sobre capital humano, capital social e práticas gerenciais. Revista de Administração da USP, 2010, 45, 4, 343-355.

4. Instituto Brasileiro de Geografia e Estatística. Pesquisa Industrial Anual - 2008. Pesquisa industrial, Rio de Janeiro, 27, 1: 1-186.

5. Instituto Brasileiro de Geografia e Estatística. Pesquisa Industrial Anual - 2007. Pesquisa industrial, 26, 1: 1-198.

6. Instituto Brasileiro de Geografia e Estatística). Indicadores IBGE: Pesquisa Industrial Mensal - Produção Física - Regional. 2011 (abril), p. 1.

\section{Cristiano Coelho, Edson R. Vieira \& Emerson Wruck.}

Instituto Brasileiro de Geografia e Estatística, UE-GO. 